Atonic Post-partum Haemorrhage (19 Cases).-In these case there was atony of the uterus and gross haemorrhage after the delivery of the placenta. At necropsy the uterus was large and poorly retracted. In every case of this group the placenta had been delivered easily, always within an hour and usuallv within a few minutes. However, the confinement had often been complicated: accidental haemorrhage in four cases, dystocia and forceps delivery under general anaesthesia in seven, and section under general anaesthesia in one. There were also two interesting cases in which a sudden severe haemorrhage about two hours after a normal third stage was the first warning of a post-partum eclampsia.

It is just as difficult to find a really adequate explanation for atonic post-partum haemorrhage as it is for atonic non-detachment of the placenta. It would in theory be quite reasonable for the uterus to be so "worn out" by a difficult second stage that it could not retract adequately either in the third stage or subsequently. In fact this type of atony is not common. Instead there are two different conditions: (1) The attached non-adherent placenta : the uterus has functioned well and easily in the first and second stages of labour, is atonic in the third stage of labour, but retracts excellently as soon as the placenta is out. (2) Post-partum haemorrhage: the uterus has often had difficulty in the first and second stages of labour, retracts excellently in the third stage and expels the placenta easily, but becomes atonic after the placenta is out. The present study does not help in the elucidation of this paradox.

Glass, M., and Rosenthal, A. H. (1948). N.Y. St. J. Med., 48, 159.

\section{TYPHOID TREATED WITH CHLOROMYCETIN}

BY

\section{F: MURGATROYD, M.D., F.R.C.P., D.T.M.}

Physician, Hospital for Tropical Diseases (University College Hospital); Deputy Director, Department of Clinical Tropical Medicine, London School of Hygiene and Tropical Medicine

In view of the present outbreak of typhoid fever at Crowthorne (Journal, May 7, p. 827) it is of topical interest to submit a preliminary and admittedly incomplete and imperfect record of treatment with chloromycetin of another case of typhoid fever recently seen in the Hospital for Tropical Diseases.

\section{Case Report}

This patient, a European aged 55, arrived by air at Southampton on April 5, 1949, three days after leaving Pakistan, where he had been on a short business trip. On his homeward flight and for the next ten days he did not feel fit, but was not ill enough to consult a doctor. On April 15 he had some shivering, sweating, and generalized aching, but continued his normal activities until April 20, on which day he himself drove 200 miles by car, finally calling at the Hospital for Tropical Diseases, where he complained of feeling feverish. Examination then revealed: temperature $103^{\circ} \mathrm{F}$. $\left(39.4^{\circ} \mathrm{C}\right.$.), but no focal signs of infection; haemoglobin $90 \%$ (Haldane) erythrocytes $4,430,000$ per c.nim., leucocytes 5,300 per c.mm. (neutrophils $66 \%$, lymphocytes $31 \%$, monocytes $3 \%$ ); no malaria parasites; slight albuminuria. He was admitted to hospital.

From April 21 to 26 he had a remittent fever $\left(101-103^{\circ} \mathrm{F}\right.$. $\left.=38.3-39.4^{\circ} \mathrm{C}.\right)$; he developed severe toxaemia, delirium, some cyanosis, a distended abdomen, and two crops of rosecoloured spots on his trunk. Relevant laboratory findings were as follows:-April 21: Blood agglutinin titre, T O negative, T $\mathbf{H} 1$ in 250 (he had not been inoculated). April 22 . Blood culture, Salmonella typhi; faeces negative. April 25: Blood agglutinin titre, T O 1 in 250, T H 1 in 1,000, T Vi 1 in 10. (The Vi agglutination was kindly done by Dr. Felix, who at the same time found somewhat higher titrés for $T O$ and $\mathrm{T} \mathrm{H}$ than those quoted; the lower figures are given, however, as they form part of the comparative series obtained at $50^{\circ} \mathrm{C}$., whereas Dr. Felix did not heat the serum beyond $37^{\circ} \mathrm{C}$.)

From April 26 to May 2 the patient was given chloromycetin (chloramphenicol, Parke Davis) orally. The initial dose was $4 \mathrm{~g}$., and this was followed by $0: 25 \mathrm{~g}$. two-hourly, a total of $22.75 \mathrm{~g}$. being given. During the first 24 hours of treatment his temperature fell to normal; thereafter it rose again and then subsided steadily during the next three days (see Chart). In the first 24 hours the patient's general condition

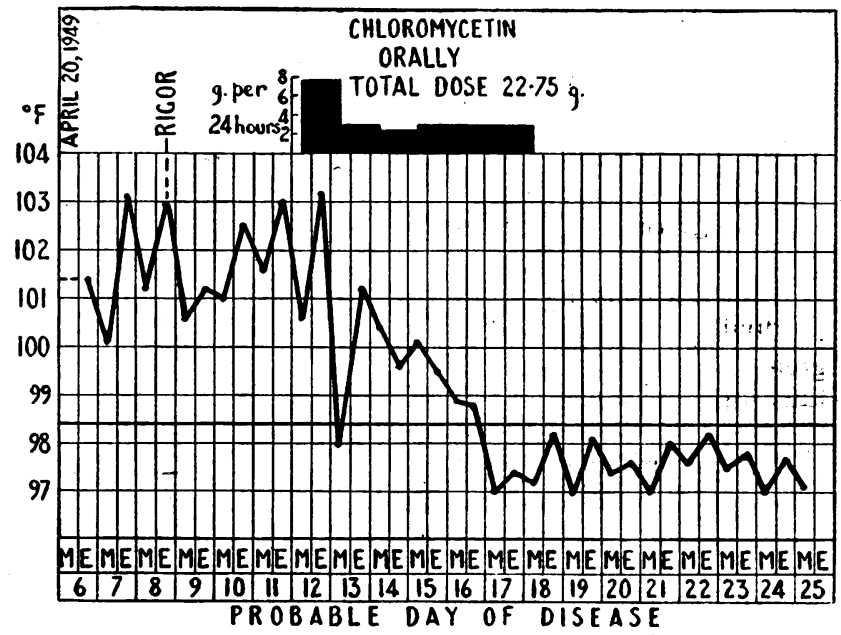

became markedly worse, and then gradually improved. Twentyfive days after the onset of the disease we now have another negative culture of faeces. On the evening of the twenty-fifth day the temperature was $97.6^{\circ} \mathrm{F} .\left(36.4^{\circ} \mathrm{C}\right.$. $)$ and on the morning of the twenty-sixth day it was $98^{\circ} \mathrm{F}$. $\left(36.7^{\circ} \mathrm{C}\right.$.).

In view of his history of indefinite but possibly prodromal symptoms during the fortnight preceding April 15 it is impossible to be sure of the exact duration of the illness before treatment, and it might be argued theoretically that the fever terminated naturally. It seems reasonable, however, to suggest that the first definite febrile manifestation was on April 15, when he had shivering, sweating," generalized aching, and malaise, and consequently that the illness was of about five or six days' duration when he was admitted to hospital. Such a duration is compatible with his initially mild toxaemia, the very slight anaemia, the white cell count, the impalpable spleen, the positive blood culture, the negative faecal culture, and the low agglutination titre found on admission to hospital ; and with the appearance of the rash, the rapid development of severe toxaemia, and the rise in agglutination titre soon

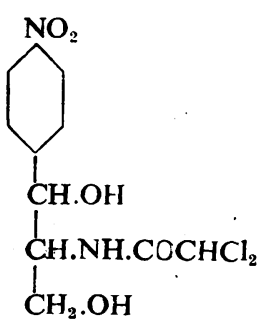
after admission. Alternatively, if the illness was of longer duration, then it certainly became exacerbated about the time of admission to hospital. In either event it seems unlikely that the patient would have improved without treatment as rapidly as he did after he was given chloromycetin: certainly his clinical condition just before treatment gave rise to considerable anxiety. Finally, the improvement with chloromycetin was what was anticipated from previous observations on typhoid fever treated with the drug (Woodward et al., 1948).

Chloromycetin originally isolated from cultures of Streptomyces venezuelae has now been synthesized (Ehrlich et al., 1947, 1948; B.M.J., 1949). It is $l-\psi-1$ p-nitrophenyl-2-dichloroacetamidopropane-1:3-diol, a white crystalline substance with bitter taste. It has considerable antibiotic activity against a wide variety of patho- 
genic orgąnisms (Smadel and Jackson, 1947, 1948 ; Payne, Knaudt, and Palacios, 1948 ; Payne, Sharp, and Knaudt, 1948 ; Smadel, Woodward, et al., 1948 ; Smadel, Leon, et al., 1948 ; Pincoffs et al., 1948), including the viruses of lymphogranuloma inguinale, psittacosis, and primary atypical pneumonia, the rickettsias, the enteric, Brucella, and relapsing-fever organisms, as well as a large number of others.

It is therapeutically effective after being given orally, but as it rapidly disappears from the blood frequent doses or high intermittent doses seem required; therapeutic dosage appears free from toxic or undesirable side-effects on man (Ley et al., 1948).

As in the present case, positive stool cultures may occasionally be found in typhoid after a course of chloromycetin, and sometimes relapses with positive blood cultures may occur. Such relapses seem to respond readily to further courses of the drug, and no evidence that the organism becomes resistant has yet been reported.

\section{REFERENCES}

British Medical Journal, 1949, 1, 672; see also British Medical Journal, 1948, 2, 428 .

Ehrlich, J., Bartz, Q. R., Smith, R. M., and Joslyn, D. A. (1947). Science, 106, 418.

Gottlieb, D., Burkholder, P. R., Anderson, L. E., and Pridham, T. G. (1948). J. Bact., 56, 467.

Ley, H. L., jun., Smadel, J. E., and Crocker, T. T. (1948). Proc. Soc. exp. Biol., N.Y., 68, 9.

Payne, E. H., Knaudt, J. A., and Palacios, S. (1948). J. trop. Med. Hyg., 5i, 68 .

Sharp, E. A., and Knaudt, J. A. (1948). Trans. R. Soc. trop. Med. Hyg., 42, 163.

Pincoffs, M. C., Guy, E. G., Lister, L. M., Woodward, T. E., and Smadel, J. E. (1948). Ann. intern. Med., 29, 656.

Smadel, J. E., and Jackson, E. B. (1947). Science, 106, 418 (1948). Proc. Soc. exp. Biol., N.Y., 67, 478.

Leon, A. P., Ley, H. L., and Varela, G. (1948). Ibid., 68, 12. Woodward,"T. E., Ley, H. L., jun., Philip, C. B., Traub, R., Lewthwaite, R., and Savoor, S. R. (1948). Science, 108, 160

Woodward, T. E., Smadel, J. E., Ley., H. L., jun., Green, R., and Mankikar, D. S. (1948). Ann. intern. Med., 29, 131.

\section{Medical Memoranda}

\section{A Clinical Note on a Vasovagal Attack of Gowers}

Sir William Gowers (1907) described prolonged seizures the symptoms of which consisted "chiefly in disturbance of some of the functions of the hypogastric nerve," usually accompanied by more or less vasomotor upset. Of sudden onset, the symptoms, at first slight, gathered strength rapidly and then slowly receded, an attack seldom lasting less than half an hour in all. To these episodes Gowers gave the name "vagal" (or, when the vasomotor disturbance was much in evidence, "vasovagal") attacks. He added that the word "vagal" was used "only as a convenient descriptive term, bringing together symptoms which cannot be easily included in a useful designation." He believed that these attacks were to be regarded as a protracted form of minor epilepsy, "drawn out, lengthened, as it were, and thereby made less intense, though not less distressing," by the absence of any tendency to termination by loss of consciousness.

Although vasovagal attacks of Gowers's type have an established place in neurological literature they are relatively uncommon, and for this reason may at times be perplexing to those unfamiliar with the clinical picture. The following case report may therefore be of some interest, since it illustrates both the nature of the symptoms and their characteristic pattern.

\section{Case History}

Shortly after sitting down to dinner one evening early in March, 1947, a healthy man aged 30 became aware of a vague sense of uncertainty and apprehension, which was at first not severe enough to prevent him taking his soup. It became more pronounced, and a feeling of swimminess was added. Thinking he was going to faint, he left the table and lay down on a sofa. Despite this the attack continued to grow in intensity, with mounting mental and physical distress. There was profuse sweating and audible intestinal gurgling, and he felt as though his bowels might be moved even against his will. He observed that his pulse rate had fallen to about 30 a minute (roughly half its normal resting value), the pulse being weak, and there was extreme pallor and coldness of face and hands. At the height of the attack, which occurred a quarter of an hour after its onset, angor animi was a marked feature. At this time the radial pulse was very slow and almost impalpable, and there was profound disinclination to make any movement. A curious hoarseness and weakness in phonation was also experienced, as though, it seems, he was unable to expire forcibly enough to set the vocal cords in full vibration. Parenthetically it may be remarked that no respiratory distress or, apparently, any definite alteration of respiratory rhythm was noticed by the patient at any time in his attack. A slow waning of the attack followed, the terminal stage of its decrescence being accompanied by a subjective feeling of intense cold, with unrestrainable chattering of the teeth and violent shivering, lasting fully ten minutes. The total duration of the attack was between half and three-quarters of an hour.

\section{COMMENT}

Unfortunately the patient was not seen during the attack. However, his full and careful account unquestionably established its identity with those described by Gowers: indeed, the similarity to Gowers's second case is strikingly close. Full physical examination the following day revealed no abnormal cardiovascular or neurological signs, and the blood pressure was normal $(125 / 80)$. An electrocardiogram taken two days later showed a heart rate of 70 , with sinus arrhythmia but otherwise normal. The patient experienced infrequent extrasystoles for about a fortnight afterwards, and then these disappeared.

It should be added that there was no personal history of similar attacks in the past, though ten years before, as a medical student on a ward round, he had once nearly fainted. The family history was essentially negative.

It is perhaps significant that the patient had returned from the Tropics only eight weeks before, to meet with the unusually severe cold of the 1946-7 winter. Further, he had had three bouts of coryza in quick succession, the last less than a week before the attack. "So far as is known there have been no recurrences.

\section{Michael Jefferson, B.M., M.R.C.P} REFERENCE

Gowers, W. R. (1907). The Borderland of Epilepsy. Churchill, London.

\section{Death following Injection of Neostigmine}

Neostigmine ("prostigmin") is known to slow the pulse markedly even in the fit patient, and in view of the widespread use of this drug in present-day anaesthetics its effect on a gravely ill patient, as exemplified in the following case, must be seriously considered.

\section{CASE Report}

A well-built but gravely ill man, aged 38, was adimitted with a history of abdominal pain for three or four days. His abdomen was distended, and there was bronchial breathing, with rales at both lung bases. His pulse was 140 and respirations 50 per minute. A careful and experienced house anaesthetist induced anaesthesia with thiopentone $0.35 \mathrm{gr}$. (23 mg.), and continued with cyclopropane. Despite the patient's poor general condition, tubocurarine, 15, 10, and $5 \mathrm{mg}$., had to be given to obtain satisfactory relaxation throughout an operation which lasted 75 minutes. Four pints (2.27 litres) of purulent fluid was evacuated through an upper abdominal incision. The stomach was found to be normal, but a perforated gangrenous appendix was revealed, making a second incision necessary. After the peritoneum was sewn up the general condition was no worse than at the beginning of the operation and certainly not immediately alarming. The pulse rate was 100 , but because of the curare the tidal exchange was not adequate and respiration had to be "assisted." At this stage $2.5 \mathrm{mg}$. of neostigmine, toge:her with $1 / 100 \mathrm{gr}$. $(0.65 \mathrm{mg}$.) of atropine, was injected through the tubing of the intravenous drip. After one or two minutes, instead of the expected respiratory response, slight cyanosis was noticed, and the pulse, which before the injection was reasonably good, was no longer perceptible. Adrenaline $0.5 \mathrm{ml}$., injected into the tubing, and cardiac massage were ineffective.

Post-mortem examination revealed collapse of the lower lobes of both lungs, dilatation of the right side of the heart, and generalized peritonitis of a very severe degree. It is improbable that the man would have survived the operation long in any case, but it is not possible to dissociate the unexpectedly sudden death with the intravenous injection given two minutes before.

R. R. MACINTOSH, D.M., D.A. 